

\title{
Prediction of peak expiratory flow rates in stunted children
}

\author{
Y ZVEREV
}

\begin{abstract}
Objective: To assess the effect of stunting on peak expiratory flow rates (PEFR) in Malawian children. Design: Cross sectional study.

Setting: Two public primary schools randomly selected in Blantyre, the largest city in Malawi.
\end{abstract}

Subjects: 266 boys and 273 girls aged six to 14 years.

Cent Afr J Med 2001;47(3):74-8

Physiology Department

College of Medicine

University of Malawi

Blantyre

Malawi
Correspondence to:

Dr Y Zverev

Physiology Department

P/Bag 360 Chichiri

Blantyre 3, Malawi

E-Mail: yzverev@yahoo.com

phypavlov@hotmail.com

Fax: (265) 674700 
Main Outcome Measures: PEFR, height, weight and age of children were determined using standard techniques. Nutritional status of children was assessed using WHO/NCHS height for age, weight for age and weight for height reference standards.

Results: The data of PEFR were analysed by regression on age and stature. One hundred children (18.6\%) were classified as stunted. None of them was under weight or wasted. The equations for prediction of PEFR were calculated separately for stunted and non-stunted children. Stature was a significant predictor of PEFR values in both groups of children. The differences between stunted and non-stunted children of both sexes in slopes and intercepts of the regression lines of PEFR on stature were non-significant. Stunted children of both sexes had significantly lower PEFR than their counterparts with normal height for age index.

Conclusions: Stunting in Malawian children aged six to 14 years is associated with decreased rate of development of PEFR in proportion to linear growth retardation. Prediction equations calculated for children with normal height for age index can be used for assessment of PEFR in stunted children.

\section{Introduction}

Peak expiratory flow rate (PEFR) is the maximal air flow rate during forced expiration following a full inspiration. ${ }^{1}$ It is an index reflecting calibre of bronchi and large bronchioles. ${ }^{1}$ In clinical sciences PEFR is used for assessment of obstructive type of ventilatory defect and response of large airways to the administration of brochodilators. In healthy persons PEFR correlates significantly with anthropometric parameters reflecting body size, particularly thoracic size. In lung function studies stature is regarded as a better index of body size than weight. ${ }^{1,2}$ Therefore, prediction equations of PEFR on stature have been calculated ${ }^{1-4}$ and widely used for evaluation of observed values of PEFR in patients and healthy persons. PEFR also correlates with other ventilatory capacity indices and the strength of respiratory muscles, as it is expiratory effort dependent.

Malnutrition in children affects the development of the ventilatory capacity. ${ }^{5}$ Wasting has particularly adverse effect on respiratory system because it impairs isotropic lung growth and weakens respiratory muscles capacity. ${ }^{6,7}$ Therefore, wasting is associated with the reduction of PEFR even though the calibre of the large airways is not affected. ${ }^{7}$ Effects of stunting on growth of ventilatory capacity is not clear as very limited data were published on respiratory functions in stunted children. Generally stunting reduces isotropic growth of the lungs. ${ }^{5}$ At the same time stunting has an adaptive value as it maintains adequate body weight and functioning at the expense of linear body growth under the conditions of chronic nutritional stress. ${ }^{8}$ Therefore, the effect of stunting on PEFR of children might be minimal. To test this suggestion we compared PEFR in stunted and non-stunted Malawian children.

\section{Materials and Methods}

The study was conducted at two primary schools selected at random from a list of state-owned schools in Blantyre, the largest city in Malawi. In each school one class per standard was surveyed, in which $50 \%$ of children were randomly selected. Thus the final selection was of 539 children of African origin (273 girls and 266 boys) who were healthy, non-smokers and received no medication at the time of the study. The sample size was estimated with $80 \%$ power at the $5 \%$ level of significance. ${ }^{9}$ All selected children and their parents gave informed consent to participate in the survey. Occupation of parents was not recorded for each child, the type and location of the schools were used as criteria of socio-economic status of children. Both schools are located in densely populated areas in Blantyre and serve predominantly low income families. Clothing of children also indicated poor economic conditions of the families. Dates of birth of the children were obtained from schools' registers and reported to the nearest whole year. As most of the children did not have birth certificates, misclassification of children by age was possible but we feel that this type of error was random.

The children were seen in small groups at the schools during normal hours of attendance, usually between $9 \mathrm{am}$ and 12 noon. The ambient temperature was about $22^{\circ} \mathrm{C}$ and relative humidity was between $40 \%$ and $60 \%$. Standing height, weight and PEFR were recorded using standard techniques. ${ }^{1,10}$ PEFR was measured with Spirocheck apparatus (Model PM2000, P K Morgan Ltd, England) with the subject standing and wearing a nose clip. Apparatus was calibrated regularly using standard technique recommended by manufacturer. The accuracy of the apparatus was $\pm 3.8 \%$, which is within recommended range. ${ }^{1}$ Three technically satisfied measurements were obtained and maximal effort was selected. Rest for at least 30 seconds was allowed between measurements. Standing height was measured to the nearest millimeter with a portable height scale. Body weight was measured to the nearest $0.1 \mathrm{~kg}$ with a portable weight scale. The subjects wore only light school uniform during measurements. Nude weights of children were obtained by subtraction of representative weight of clothing at each age group from the observed weight of each pupil. The height and weight scales were calibrated regularly. The same equipment and observers were used for all subject evaluation.

Nutritional status of children was established using weight for age (W/A), height for age (H/A) and weight for height $(\mathrm{W} / \mathrm{H})$ indices compared to WHO/NCHS reference data. ${ }^{11}$ Values of W/H, H/A and W/A lower than two standard deviations units from WHO medians were 
considered cut off points for wasting, stunting and underweight respectively. ${ }^{10}$

The data were analysed with Epi Info 2000 and Microsoft Excel software. The means and standard deviations of each variable were calculated. Variables of different groups of children were compared using $t$ statistics and MannWhitney test. The level of statistical significance was fixed at $p<0.05$. Single and multiple regression analysis were performed. Comparison of the regression lines of stunted and non-stunted children was made by analysis of covariance in terms of slopes and intercepts. This statistical approach is widely used for assessment of effects of various physiological and pathological conditions on ventilatory capacity indices. ${ }^{12,13}$

\section{Results}

According to $\mathrm{H} / \mathrm{A}$ index relative to WHO/NCHS reference data ${ }^{11} 100$ children ( 52 boys and 48 girls) were classified as stunted. None of the children was wasted or underweight in our study sample. Table I shows descriptive statistics for height and PEFR of stunted and non-stunted boys and girls of different age groups. Since standard deviations of mean values of PEFR were large, the median values and range were calculated, reported and used for statistical analysis.

The values of PEFR increased progressively with increasing age and body size in both groups of children.

Stunted children had significantly lower values of PEFR than children with normal value of $\mathrm{H} / \mathrm{A}$ index in most of the age groups. Linear relationship with statistically significant correlations $(\mathrm{p}<0.001)$ were found between the PEFR values and stature or age in stunted and non-stunted groups of children of both sexes (Figures I and II). The single and multiple regression equations relating height and age with PEFR are given in Table II along with correlation coefficients. The $p$ values for differences between slopes and intercepts of the regression lines of children with different $\mathrm{H} / \mathrm{A}$ index are given in Table III.

Table II: Equations for prediction of PEFR in stunted and non-stunted children.

\begin{tabular}{lrlr}
\hline $\begin{array}{l}\text { Non-stunted children } \\
\text { Equation }\end{array}$ & $\mathrm{r}$ & $\begin{array}{l}\text { Stunted children } \\
\text { Equation }\end{array}$ \\
\hline Boys & & & $\mathrm{r}$ \\
PEFR $=4.958 \mathrm{H}-401.8$ & 0.96 & PEFR $=3.761 \mathrm{H}-274.0$ & 0.84 \\
PEFR $=25.135 \mathrm{~A}+10.0$ & 0.97 & PEFR $=14.267 \mathrm{~A}+36.9$ & 0.78 \\
PEFR $=30.062 \mathrm{~A}-0.989 \mathrm{H}+92.8$ & 0.95 & PEFR $=9.177 \mathrm{H}-22.178 \mathrm{~A}-699.90 .77$ \\
& & & \\
Girls & & & 0.88 \\
PEFR $=5.379 \mathrm{H}-457.2$ & 0.99 & PEFR $=4.751 \mathrm{H}-389.8$ & 0.89 \\
PEFR $=29.357 \mathrm{~A}-34.7$ & 0.97 & PEFR $=22.577 \mathrm{~A}-36.5$ & 0.65 \\
PEFR $=49.919 \mathrm{~A}-4.597 \mathrm{H}+374.0$ & 0.96 & PEFR $=3.520 \mathrm{H}-1.765 \mathrm{~A}-232.0$ & 0.
\end{tabular}

Table I: Descriptive statistics for height and PERF of stunted (S) and non-stunted (NS) Malawian children.

\begin{tabular}{|c|c|c|c|c|c|c|c|}
\hline $\begin{array}{l}\text { Age } \\
\text { (years) }\end{array}$ & H/A Index & $\mathrm{N}$ & $\begin{array}{l}\text { Boys } \\
\text { Height' cm }\end{array}$ & $\mathrm{PEFR}^{a t} 1 / \min$ & $\mathrm{N}$ & $\begin{array}{l}\text { Girls } \\
\text { Height' cm }\end{array}$ & PERF" $1 / \min$ \\
\hline \multirow[t]{2}{*}{6} & $s$ & 5 & $102.2(2.1)^{\star}$ & $116.3(29.1)$ & 6 & $107.9(0.4)^{\star}$ & $93.5(48.8)$ \\
\hline & NS & 22 & $115.3(7.9)$ & $131.7(100.6)$ & 24 & $112.8(3.0)$ & $139.4(114.2)$ \\
\hline \multirow[t]{2}{*}{7} & $s$ & 7 & $108.2(2.1)^{\star}$ & $135.5(48.5)^{\star \star}$ & 8 & $110.5(0.6) 8$ & $117.5(47.4)^{\star}$ \\
\hline & NS & 31 & $117.5(4.5)$ & $209.3(78.1)$ & 26 & $117.1(3.5)$ & $177.5(81.0)$ \\
\hline \multirow[t]{2}{*}{8} & s & 6 & $114.2(1.5)^{\star}$ & $108.5(58.4)^{\star}$ & 5 & $110.0(2.2)^{*}$ & $122.1(53.7)^{\star \star \star}$ \\
\hline & NS & 22 & $122.5(4.4)$ & $216.5(130.0)$ & 30 & $123.1(4.5)$ & $212.0(110.3)$ \\
\hline \multirow[t]{2}{*}{9} & $s$ & 6 & $118.6(2.3)^{\star}$ & $172.3(5.7)^{\star}$ & 5 & $113.6(2.5)^{\star}$ & $149.9(117.9)^{\star \star}$ \\
\hline & NS & 24 & $130.3(3.3)$ & $241.8(101.0)$ & 24 & $124.6(4.0)$ & $249.7(103.9)$ \\
\hline \multirow[t]{2}{*}{10} & $S$ & 5 & $122.5(9.8)$ & $173.1(56.6)^{\star}$ & 4 & $118.5(2.3)^{\star}$ & $169.0(67.8)$ \\
\hline & NS & 20 & $131.7(4.8)$ & $302.8(134.2)$ & 19 & $132.0(4.2)$ & $275.3(121.0)$ \\
\hline \multirow[t]{2}{*}{11} & S & 6 & $125.4(3.2)^{\star}$ & $175 .(24.6)^{\star \star}$ & 5 & $126.4(3.3)^{\star}$ & $181.2(53.6)^{\star \star}$ \\
\hline & NS & 18 & $140.4(3.9)$ & $331.3(103.8)$ & 28 & $138.9(7.0)$ & $278.1(162.1)$ \\
\hline \multirow[t]{2}{*}{12} & $S$ & 5 & $125.3(6.4)^{\star}$ & $130.3107 .2)^{\star}$ & 6 & $131.0(4.1)^{\star}$ & $139.3(108.0)^{\star}$ \\
\hline & NS & 22 & $143.0(7.1)$ & $300.6(129.9)$ & 24 & $145.2(6.2)$ & $311.6(1147.8)$ \\
\hline \multirow[t]{2}{*}{13} & $s$ & 7 & $130.0(1.2)^{\star}$ & $180.4(64.7)^{\star \star}$ & 4 & $134.6(7.6)^{\star}$ & $216.0(124.4)^{* \star}$ \\
\hline & NS & 26 & $148.7(5.8)$ & $301.9(189.9)$ & 22 & $150.0(4.8)$ & $336.3(205.7)$ \\
\hline \multirow[t]{2}{*}{14} & $S$ & 5 & $139.0(1.7)^{\star}$ & $244.0(110.2)^{\star}$ & 5 & $144.5(2.1)^{\star}$ & $271.5(127.0)^{\star}$ \\
\hline & NS & 29 & $154.2(6.2$ & $341.9(234.0)$ & 28 & $154.4(50)$ & $380.9(203.3)$ \\
\hline
\end{tabular}

\# Figures are means and standard deviations (in brackets).

\#\# Figures are medians and range (in brackets).

* Indicates significant difference between stunted and non-stunted children at $p<0.01$,

*t at $p<0.05$. 
Figure I: Linear relationship between PEFR and height (a), weight (b) or age (c) in stunted (S) and non-stunted (NS) Malawian boys.

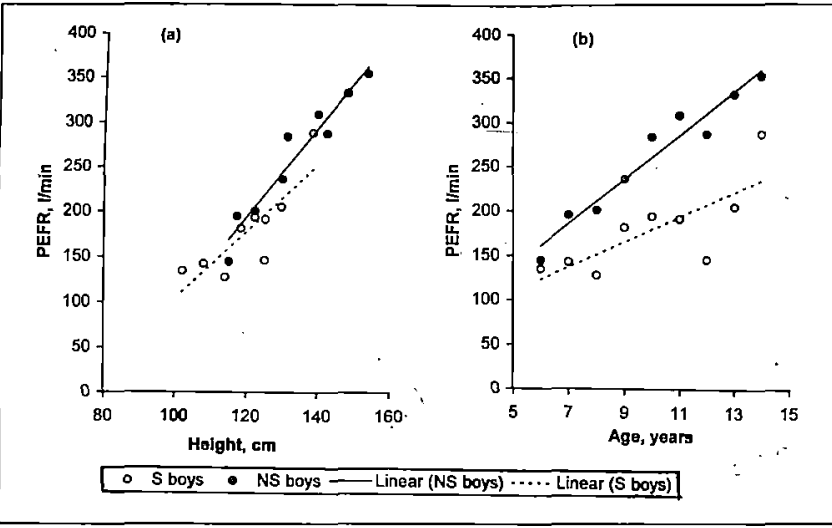

Figure II: Linear relationship between PEFR and height $(a)$, weight $(b)$ or age (c) in stunted (S) and non-stunted (NS) Malawian girls.

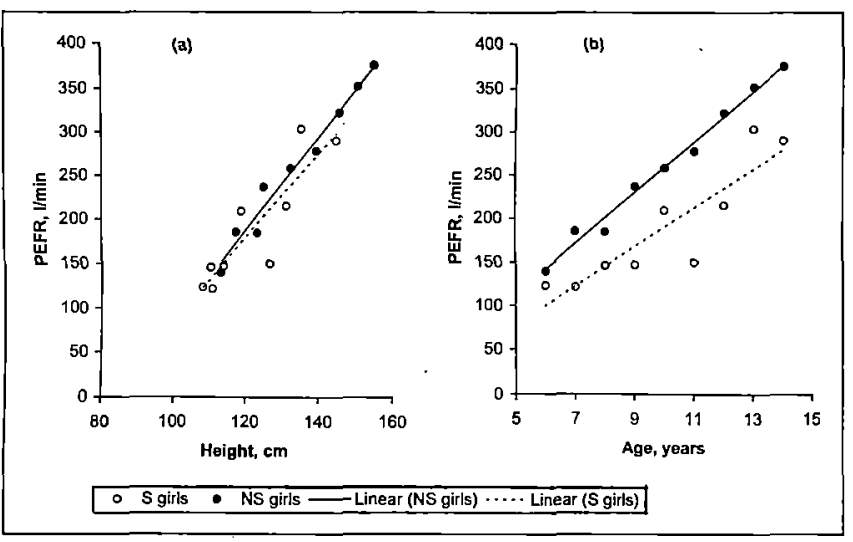

Table III: Level of statistical significance ( $p$ values) of differences between regression lines for stunted and nonstunted children.

\begin{tabular}{lll}
\hline $\begin{array}{l}\text { Independent } \\
\text { Variable }\end{array}$ & $\begin{array}{l}\text { PEFR } \\
\text { Slope }\end{array}$ & Intercept \\
\hline Boys & & \\
Age & 0.018 (S) & 0.301 (NS) \\
Height & 0.446 (NS) & 0.351 (NS) \\
Age/Height & 0.079 (NS) (Age) & 0.164 (NS) \\
Girls & 0.148 (NS) Height & \\
Age & & \\
Height & 0.060 (NS) & 0.485 (NS) \\
Age/Height & 0.246 (NS) & 0.426 (NS) \\
& 0.086 (NS) (Age) & 0.168 (NS) \\
\hline
\end{tabular}

$S=$ significant.

NS = non-significant .

\section{Discussion}

In terms of PEFR, stunted children of different age groups were two to four years behind their Malawian counterparts with normal H/A index. Slopes of the regression lines of PEFR on age were significantly lower in stunted than in non-stunted boys, which indicated low rates of increase of PEFR with age. After height has been allowed for, the difference between the two groups of boys was not significant. The inclusion of the second predictor variable did not increase correlation coefficients and effectiveness of the overall regression (Tables II and III). The difference between slopes of the regression lines of the two groups of girls did not reach the level of statistical significance but the trend was similar.

The present study confirms earlier findings ${ }^{1-3,14,15}$ that body size is a significant predictor of ventilatory capacity indices in children with normal nutritional status. Our data indicate that stature can also be used for prediction of PEFR in stunted boys and girls as association between PEFR and this parameter was strong and significant in all groups of children. The differences between children with low and normal $\mathrm{H} / \mathrm{A}$ index in slopes and intercepts of the regression lines of PEFR on stature or weight were not significant. Therefore children of similar body size had similar PEFR regardless of $\mathrm{H} / \mathrm{A}$ index which indicates that stunting reduces isotropic growth of the respiratory system in proportion to retardation of linear body growth. Our data also provide indirect evidence that respiratory muscle strength is not affected by stunting as the opposite should reduce PEFR. This pattern is different from wasting and achondroplasia, which reduce ventilatory capacity out of proportion to what would be expected if persons had normal body size indices. ${ }^{5.16}$

Nineteen percent of children in this study had H/A index two standard deviations below WHO/NCHS reference data $^{11}$ and were classified as stunted. Several authors ${ }^{17,18}$ have demonstrated that these standards are relevant for Malawi, as growth of children from well off families closely resembles WHO/NCHS medians for height and weight. Therefore, it was reasonable to assume that chronic under nutrition was responsible for low H/A index in Malawian children rather than genetic factors.

Our study indicates that further investigation is required to highlight the effect of under nutrition on growth of ventilatory capacity in children, particularly during adolescence as Malawian children exhibit considerable catch up growth during this period. ${ }^{19}$ In conclusion, stunting in Malawian children aged six to 14 years is associated with decreased rate of development of PEFR in proportion to linear growth retardation. Stature is a significant predictor of PEFR in stunted children. Prediction equations calculated for children with normal height for age index can be used for assessment of PEFR in stunted children.

\section{Acknowledgements}

The technical assistance of $\mathrm{Mr} \mathrm{D}$ Mbewe and Miss $\mathrm{K}$ Mpesi is gratefully appreciated. The author is most grateful to $\mathrm{Mr} \mathrm{H}$ Misiri, Community Health Department, for suggestions in statistical analysis of the data. 


\section{References}

1. Cotes JE. Lung function: assessment and application in medicine. 5th ed. Oxford: Blackwell Scientific Publication, 1992:768.

2. Patrick JM, Patel A. Ethnic differences of lung function in children: a cross-sectional study in innercity Nottingham. Ann Hum Biol 1986;13:307-15.

3. Mukhtar MSR, Rao GMM, Morghom LO. Peak expiratory flow rates in Libyan adolescents. Ind $J$ Physiol Pharmac 1989;33:223-7.

4. Gupta P. Nutritional and lung function profile of boys belonging to east Delhi. J Ind Med Ass 1997;95:176-8.

5. Ong TJ, Mehta S, Ogston, S. Prediction of lung function in the inadequately nourished. Arch Dis Childh 1998;79:18-21.

6. Zaman K, Baqui AH, Yunus M, Sack RB, Chowdhury HR, Black RE. Malnutrition, cell-mediated immune deficiency and acute upper respiratory infections in rural Bangladeshichildren.Acta Pediat 1997;86:923-7.

7. Arora NS, Rochester DF. Respiratory muscle strength and maximal volume ventilation in undernourished patients. Am Rev Resp Dis 1982;126:5-8.

8. Balam G, Gurri F. A physiological adaptation to undernutrition. Ann Hum Biol 1994;21:483-9.

9. Armitage P, Berry G. Statistical methods in medical research. 3rd ed. Oxford: Blackwell Scientific Publication, 1994:620.
10. Gibson RS. Principles of nutritional assessment. New York, Oxford University Press, 1990.

11. WHO. Measuring changes in nutritional status. Geneva, World Health. Organisation, 1982.

12. Greksa LP, Spielvogel H, Caceres E, ParedesFernandez L. Lung function of young Aymara highlanders. Ann Hum Biol 1987;14:533-42.

13. Malik SL, Singh IP. Ventilatory capacity among highland Bods: a possible adaptive mechanism at high altitude. Ann Hum Bio. 1979;6:471-6.

14. Deshpande JN, Dahat HB, Shirole CD, Pande AH. Pulmonary functions and their correlation with anthropometric parameters in rural children. Ind $J$ Ped 1983;50:375-8.

15. Aitken ML, Schoene RB, Franklin J, Pierson DJ. Pulmonary function in subjects at the extremes of stature. Am Rev Resp Dis 1985;131:166-8.

16. Stokes DC, Wohl ME, Wise RE, Fairclough DL. The Iung and airways in achondroplasia. Do little people have little lungs? Chest 1990;98:145-52.

17. Quinn VJ, Chiligo-Mpoma MO, Simler K, Milner J. The growth of Malawian pre-school children from different socio-economic groups. European J Clin Nutr 1995;49:66-72.

18. Chimwaza BM. Food and nutrition in Malawi. Ph.D. thesis, University of London 1982.

19. Zverev Y, Gondwe M. Growth of urban school children in Malawi. Ann Hum Biol (At press). 


\section{(c) (1) (9)}

This work is licensed under a

Creative Commons

Attribution - NonCommercial - NoDerivs 3.0 License.

To view a copy of the license please see:

http://creativecommons.ora/licenses/bv-nc-nd/3.0/ 